\title{
Elementos de la tragedia clásica en el teatro de José Ricardo Morales*
}

\section{Classical Tragedy Elements in José Ricardo Morales' Theater}

\author{
M. ${ }^{a}$ Teresa Santa María Fernández \\ Universidad Internacional de La Rioja \\ teresa.santamaria@unir.net \\ ORCID iD: https://orcid.org/0000-0003-0281-7754
}

\section{RESUMEN}

José Ricardo Morales es un escritor español exiliado en Chile tras la Guerra Civil. Su teatro resulta novedoso y contiene una profunda reflexión sobre el absurdo del hombre y de la sociedad contemporánea. Analizamos en este artículo el uso, dentro de toda su dramaturgia, de los personajes, la trama basada en el diálogo y la reacción que busca en el público el escritor desterrado. Estos tres elementos, con los que el propio Morales estudió las tragedias de García Lorca, son utilizados por el autor desterrado para provocar el distanciamiento y la reflexión profunda por parte del público o de los lectores. Unos personajes distanciados y una trama basada en un diálogo irónico, pero que induce a la reflexión objetiva y lejana de cuanto sucede sobre el escenario, provocarán que el público reflexione sobre esa realidad contemporánea que con tanto acierto refleja nuestro dramaturgo.

Palabras Clave: José Ricardo Morales; exilio; teatro; mitos; tragedia clásica.

\begin{abstract}
José Ricardo Morales is a writer who was exiled in Chile after the Spanish Civil War. His theatre is very original and has a deep reflexion about the contemporaneous man and world's absurd. In this articule, we're analizing the use, inside all his dramaturgy, of the characters, of a plot based on dialogue, and of the reaction that he's seeking on the pubic. These three elements, with which Morales studied García Lorca's tragedies, are used by the exiled author to cause a estrangement and a deep reflection inside the pubic or the readers. Distancing characters, a plot based on am ironic dialogue but that leads to a deep and distant reflection of what's happening
\end{abstract}

* Este artículo se incluye dentro del proyecto La historia de la literatura española y el exilio republicano de 1939 (FFI2013-42431-P), financiado por el Ministerio de Economía y Competitividad. 
on the stand will make the audience think about this modern reality that our writer shows so accurately.

Key words: José Ricardo Morales; Exile; Theater; Myths; Classical Tragedy.

José Ricardo Morales (Málaga 1915, Santiago de Chile 2016) es uno de los dramaturgos exiliados en 1939 que vivió y escribió hasta sus más de cien años en su tierra de acogida. Este escritor, profesor universitario y académico conoce con gran profundidad y detalle la tradición y cultura clásicas, como así lo demuestran no solo sus ensayos sino su acertado dominio de las etimologías de vocablos procedentes del latín o del griego ${ }^{1}$. Por tanto, no ha de resultar extraño que haya compuesto durante su destierro en Chile varias obras basadas en mitos procedentes de dicha literatura. Nos referimos, por ejemplo, a cinco de las seis piezas que constituyen el volumen de su Teatro mítico y que van desde el recuerdo a Homero en La odisea (1965) hasta la aparición de las tres Parcas en El destinatario, pasando por mitos como el de Orfeo en Orfeo y el desodorante. También encontramos la actualización de tragedias griegas propiamente dichas, como ocurre en Hay una nube en su futuro, donde no seguirá a Esquilo en su Prometeo encadenado, respecto al castigo cruel que los dioses infligieron a Prometeo por robarles el fuego; o bien, en el caso de su Edipo reina o la planificación, donde aparecen numerosos guiños y alusiones a Edipo, rey de Sófocles.

Tanto en su «Autobiograma» (Morales 1992: 26-27) como en la introducción que el profesor Manuel Aznar (2009: 23-24) realiza a la edición de su Teatro completo, se consignan cuatro períodos en su obra dramática. En todas estas etapas podremos comprobar cómo Morales consigue mantenerse fiel a esa premisa suya de que «la originalidad mayor consiste en reconocer el origen, no en negarlo» (Morales 2012: 189) y en piezas correspondientes a todos esos períodos encontraremos rastros y elementos de la tragedia griega. Por tanto, nos proponemos estudiar el teatro de José Ricardo Morales, con el mismo enfoque que él empleó para el de García Lorca en un artículo que lleva por título «La tragedia en el teatro de Federico García Lorca», donde reflexiona sobre la afirmación de que «Hay que volver a la tragedia», que el escritor granadino realizó en 1934, y donde el escritor exiliado vincula con Bodas de

${ }^{1}$ Esa pasión por las etimologías y significados originarios de los vocablos griegos se puede observar no solo en los ensayos más relacionados con la literatura, como los que se integran bajo el epígrafe de «Mímesis dramática», sino también en otros dedicados a otras manifestaciones culturales, como «Estilo, pintura y palabra» (Morales 2012: 329-354 y 8331127). Para una visión completa de la obra teatral de José Ricardo Morales, pueden consultarse los trabajos de Haydée Ahumada, Claudia Ortego y Pablo Valdivia que aparecen en la Bibliografía citada. 
sangre, La casa de Bernarda Alba y Yerma el 'mito de ligazón' o de linaje de la Poética de Aristóteles. Dicha idea de 'mito de ligazón', en opinión de Morales, «se encuentra establecido en tres estratos: el de los personajes — según la vida supuesta que tienen en el drama-; el del 'mito', constituyente del drama como 'trama', y el del público que asiste a la representación del personaje y del mito» (Morales 2012: 503).

\section{Personajes}

Resulta indudable la importancia directa de la tragedia clásica en la dramaturgia de Morales, especialmente, en las ya aludidas cinco piezas de las seis que conforman su Teatro mítico (La odisea, El destinatario, Orfeo y el desodorante, Hay una nube en su futuro y Edipo reina o la planificación). Por otro lado, no podemos dejar de comprobar cómo José Ricardo Morales vuelve a acudir, como muchos de los dramaturgos desterrados tras la Guerra Civil española - M. ${ }^{\mathrm{a}}$ Luisa Algarra, Max Aub, Agustí Bartra, José Bergamín, José M. ${ }^{a}$ Camps, Ambrosi Carrion, Isaac Díaz Pardo, José Ramón Enríquez, León Felipe, Agustín Gómez Arcos, Sigfredo Gordon Carmona, María de la O Lejárraga, José Martín Elizondo, Carlota O’Neill, Pedro Salinas o María Zambrano (Santa María 2016: 249-251)_, a las fuentes clásicas griegas, para actualizar, distanciar o satirizar un mito y referente anterior, dentro de una de las grandes líneas temáticas, la de "Teatro mítico", en que incide la dramaturgia del exilio español (Doménech 2013: 65-66). No obstante, la elección de un personaje mitológico - Ulises, las Parcas u Orfeo-y el seguimiento más o menos fiel de las líneas argumentales básicas de una tragedia anterior - Prometeo y Edipo - no constituyen en el caso de nuestro dramaturgo una garantía de continuar a rajatabla con los postulados y características del mito o la tragedia elegidos. Tampoco se inclina, como es el caso de su admirado Lorca, por un «conflicto entre parientes», donde «junto con la preocupación por los linajes, se manifiesta la imposibilidad de generación» (Morales 2012: 509).

Además, si de entre esas cinco obras dramáticas ya citadas, y en las que la «originalidad» trágica se hace más patente, solo en dos de ellas Morales recurre a protagonistas procedentes de la tragedia griega, igual sucede en otras piezas dramáticas de nuestro escritor, donde encontramos personajes con nombres clásicos, pero sin reminiscencias trágicas. De esta manera, aparecen personajes de raigambre homérica, como Héctor - solo aludido y en nada similar al héroe griego al que debe el nombre- en Pequeñas causas (Morales 2009: 166); o bien, Mentor y Circe en La teoría y el método y en El Canal de la Mancha (ibid.: 418-436 y 463-486, respectivamente).

Pero también se alude a personajes míticos como las Furias, aunque no sean al principio más que los chicos que han irrumpido en casa de la Tía Laura en El juego de la verdad (ibid.: 277, 279, 285 y 289) y cuya manera de vencerlas 
se vincula con el tema del destino, tan característico, por otro lado, de la tragedia clásica:

GERMÁN: ... Consultemos, averigüemos el destino. (Se dirige a la biblioteca y coge un libro.) Aquí está nuestro oráculo. Que hable.

ALBA: ¿Quién es ese señor?

GERMÁN: El adivino. Es un poeta. Vais a ver. Se hacen correr las páginas del libro, señalamos un verso y el poeta nos vaticina el porvenir... (ibid.: 277).

No podemos olvidar que esa alusión al oráculo ciego, al libro que se abre por una página al azar, será también el medio en que Germán lleve a cabo su revancha contra Victoria al final del Acto Segundo: «GERMÁN: ... Elena, tú eres inocente: acércate a la biblioteca; coge el libro de versos. Sí, el que empleamos en el juego. Ahí a la derecha. Ábrelo. Página ciento cinco. Dinos, ¿qué ves?» (ibid.: 308). De esta forma, será verdad, como dice en el último acto Victoria que «Lo ha querido el destino. Las furias van a dormir entre nosotros.» y que ella quedará petrificada pues «está fuera del tiempo. Quedó fija en la imagen de las furias que su delirio le hace ver» (ibid.: 314 y 317).

Otro personaje mitológico que también resulta relevante en Hay una nube en su futuro, de 1965, es el de Musa, esa musa que inspira a los científicos y no a los poetas (Morales 1973: 12), y cuya compañera, LA SEÑORA KLIO o musa de la historia, aparece en No hay que perder la cabeza o las preocupaciones del Doctor Guillotin (Morales 2009: 955-1010) ya que, como el mismo Morales recuerda en su ensayo «La disidencia del escritor. Una premeditación», «los griegos especializaron algunas de las muchas propiedades del dios Thoth, atribuyéndoselas a las musas» (Morales 2012: 61). Mientras que las parcas que protagonizan El destinatario (2002) -Átropos, Cloto y Láquesis-, y que aparecen aludidas como una posibilidad de explicación para la 'P' gigante que se encuentra Carpi a principio de Edipo reina o la planificación (Morales 2009: 1372 y 1339), nos recuerdan la forma en que esas triadas de personajes femeninos son también utilizadas por parte de otros dramaturgos del exilio como Alberti y sus tres furias o gorgonas en El adefesio ${ }^{2}$ o como las tres parcas en La niña guerrillera ${ }^{3}$ de José Bergamín. Personajes que, por otro lado, evocan a esas bacantes que irrumpen en el desenlace de Orfeo y el desodorante o el último viaje a los infiernos (ibid.: 953) y que de nuevo podemos asociar con

${ }^{2}$ Alberti (2006: 273). Como bien anota el editor de estas dos piezas, Gregorio Torres Nebrera, las figuras de Uva, Aulaga y Gorgo recuerdan no solo a las tres furias o las tres gorgonas (ibid.: 248, nota 18), sino a las tres hilanderas-parcas (ibid.: 273, nota 36).

3 «(Al decir las viejas los últimos versos, la Niña se ha echado en el suelo quedando aparentemente dormida. Entran entonces las tres muchachas nevadas, más irreales que nunca, como figuración de hadas en los cuentos. Las viejas, entre tanto, quedan alrededor de la Niña dormida, viéndoseles entre las manos, ahora, la rueca, el huso y las tijeras, con los que laboran, evocando la representación habitual de las Parcas.).» (Bergamín 1945: 77). 
la reacción final de las tres hilanderas-parcas en El adefesio o de ese Coro de las mujeres que encontramos en la versión de Hécuba que realizó José Bergamín y que lleva por título La hija de Dios ${ }^{4}$.

Por último, conviene destacar cómo Morales, al igual que otros dramaturgos exiliados, si bien no vuelve a mirar desde abajo a los «héroes» trágicos y desmitifica, en buena medida, su importancia, sí presta especial importancia a ese personaje colectivo y anónimo, esencial en la tragedia griega, su coro ${ }^{5}$. Pero, el primer paso hacia ese personaje que funciona en muchas de las tragedias griegas «a manera de cierre o comentario» reflexivo tras el diálogo de los personajes (Fuentes 2007: 31) se inicia con el carácter anónimo de muchos de los personajes que aparecen en su teatro. Ya en su primera obra, Burlilla de Don Berrendo, Doña Caracolines y su amante, de 1938, nos encontramos con los Vecinos, aunque no hablan, o con los Dos Guardias, a los que se les alude como UN GUARDIA y EL OTRO GUARDIA (Morales 2009: 61-62), en sus respectivas entradas. O bien, menciona a algunos personajes por la profesión que desempeñan como EL AGENTE DE SEGUROS de El torero por las astas, escrita en 1983 (ibid.: 1172) o EL AGENTE DE PUBLICIDAD, EL ASESOR CIENTÍFICO o EL INSPECTOR de Orfeo y el desodorante (ibid.: 896).

Tampoco tienen nombres propios los cinco personajes que se incluyen en De puertas adentro, EL MARIDO, LA MUJER, LA MADRE, EL VISITANTE, UN VECINO (ibid.: 133); EL HOMBRE y LA MUJER en la obra de 1966, Oficio de tinieblas (ibid.: 522), LA MUJER del monólogo que escribió en 1967 y que lleva por título Las horas contadas (ibid.: 533-540); EL ORADOR DE TURNO en Recomendaciones para cometer el crimen perfecto, de 1988 (ibid.: 667-676); o bien EL HOMBRE del monólogo Cama rodante abandonada en una plaza pública (ibid.: 699-708), en una de sus obras más recientes, escrita en 2003.

Otras veces aparecen personajes a los que se les alude por el papel o función que realizan dentro de la obra, como LA QUE NADIE ESPERABA en $L a$ teoría y el método, de 1964 (ibid.: 418); LA NIÑA QUE CANTA LOS NÚMEROS en El oniroscopio, escrita en 1995 (ibid.: 620); o EL REPRESENTANTE DE LOS OTROS en Hay una nube en su futuro, de 1965 (ibid.: 732).

${ }^{4}$ « $\mathrm{Oh}$, qué cruel espanto! ¡Arrastran su cuerpo ensangrentados por la llanura y hasta los grandes y furiosos toros huyen corriendo del impetuoso avance feroz de sus caballos, que blanquean su galope enloquecido a través de los campos, abriendo surcos con su destrozado cuerpo y sembrándolos de sus vivos despojos! ¡Vamos nosotras todas a seguirla en la santidad de su martirio! ¡ Ved que entre las humaredas y el polvo empieza a encenderse también de sangre el horizonte; y que nosotras no veremos ya la luz de este día!» (Bergamín 1945: 72-73).

${ }^{5}$ Respecto al papel del coro en la tragedia, ya reconocía Aristóteles que el coro «debe ser considerado como uno de los actores, formar parte del conjunto y contribuir a la acción, no como en Eurípides, sino como en Sócrates» (Aristóteles 1974: 11). 
E incluso cobran solo realidad cuando, paradójicamente, representan su papel dentro de la obra, como ocurre con LA MUJER de Los culpables: «MARÍA GARCÉS: No. Acepto a esa María Garcés ficticia, no por las pruebas, que son falsas, sino porque me identifico plenamente con ese personaje que inventaron» (ibid.: 340). También puede suceder que ni siquiera posean entidad, como la MUJER que monologa con el ausente Juan en A ojos cerrados, de 1947 (ibid.: 183-196) o esas voces que resuenan como simples conversaciones sin emisor reconocible en El material, escrita en 1972 (ibid.: 587). Curiosamente, esa deshumanización de los personajes le lleva a poner sobre la escena a LA COSA HUMANA en la obra homónima de $1966^{6}$ y a TODO EL MUNDO en Prohibida la reproducción (1963-1964), aunque sean «monigotes o espantajos de tela» que solo sirven para hacer desaparecer a Liberón, «arrastrado por el vaivén violento del oleaje humano» (ibid.: 415).

Y esa alusión a LOS DOLIENTES y a la GENTE DEL PUEBLO, como aparece, por ejemplo, en Bárbara Fidele (ibid.: 198), se asemeja al uso que podemos encontrar en tragedias griegas como Hécuba o Medea de Eurípides, cuando se hace referencia a ese personaje colectivo que representa a un pueblo como "Coro de cautivas» y "Coro de mujeres», respectivamente (Eurípides 1998: 364 y 170) y donde se alude de manera específica a la función del coro como representante del pueblo o de la polis dentro de la tragedia. De ahí que incluso haya servido como título genérico en algunas tragedias griegas como Los Heraclidas de Eurípides, Los persas de Esquilo, o bien, ya vinculada y personificada en femenino, para Las fenicias, Las suplicantes y Las troyanas del propio Eurípides. Una feminización del término que sirvió, sin duda, como inspiración para la obra de otra dramaturga exiliada en 1939, Las republicanas, de Teresa Gracia (1984) o que corresponden con «EL CORO, que son las mujeres del pueblo que acompañan a Teodora» en La hija de Dios (Bergamín 1945: 11).

Por otro lado, será en Bárbara Fidele (1944-1946) donde encontraremos el primer diálogo con tres personajes, EL SOLDADO, UNO DEL GRUPO y EL DESCONOCIDO, que funcionan como Corifeos o voces más destacadas dentro del Coro. En efecto, en la penúltima escena del Sexto y Último Cuadro de este «caso de conciencia», los tres responden alternativamente a la protagonista para ofrecernos su opinión sobre lo ocurrido. EL SOLDADO actúa como moderador que va otorgando la palabra a unos y a otros, pero también es quien emite los dos juicios de valor con que se abre y se cierra dicha escena: «BÁRBARA FIDELE: (Desprendiéndose de quienes la retienen.) ¿Qué hice, Dios

${ }^{6}$ Tal y como el propio dramaturgo comenta en nota al pie junto al subtítulo y subgénero, «LA COSA HUMANA (Su funcionamiento y modo de empleo.) Prospecto para el uso de nuestros clientes» de la obra: «Todo este encabezamiento, así como el resto del prospecto, se escucha por el altavoz. El lector no aparece en escena. Las acotaciones que denotan acción corresponden al personaje que representa La Cosa Humana.» (Morales 2009: 507). 
mío? EL SOLDADO: Dar suelta a las violencias de tu corazón.» (Morales 2009: 262) y «BÁRBARA FIDELE: ¿Estáis todos contra mí? ¿Cómo debo interpretar vuestro ambiguo lenguaje? EL SOLDADO: Palabras de doble sentido, malas para referirse a una conducta severa, a una firme servidora de la fe» (ibid.: 264). Y conviene recordar aquí que esos soldados anónimos, como el Guardián que aparece en la Antígona de Sófocles o los parodiados por su fanfarronería ya desde el Miles gloriosus de Plauto, serán uno de los arquetipos que más se repitan en sus obras pues, a las ya citadas, habría que añadir $L a$ grieta (1963) y sus SOLDADO PRIMERO y SOLDADO SEGUNDO (ibid: 362).

Como hemos podido ver, el carácter colectivo o anónimo de los personajes que forman el coro o la alusión a personajes con una larga tradición clásica resultan constantes en la obra de Morales y coinciden con su objetivo de actualizar los mitos, tramas y personajes: "Yo siempre he sostenido que el teatro no es sólo acción, sino también actualización. El actor no actúa (quien actúa es el personaje) sino que actualiza. Si yo vivo en un mundo actual mi teatro tiene que ser actual» (Gómez y Deluca 1992: 87). Pero, además, cabe señalar que ese anonimato o intención de aludir a los personajes de una manera determinada refleja en la dramaturgia del escritor desterrado la deshumanización de dichos personajes, con la finalidad de que el espectador no se encariñe ni se identifique con ellos. De ahí que algunos de los actuantes de sus piezas sean nombrados con letras, como los dos hombres y mujeres que aparecen referenciados bajo una simple letra (A, B, C, y D) en El segundo piso, de 1968 (Morales 2009: 541-556); o con meras cifras y letras como ocurre con los cuatro agentes -EL AGENTE B1, EL AGENTE N4, EL AGENTE S8 y EL AGENTE X9- en Un marciano sin objeto, escrita en 1967 (ibid.: 775-810). Otra forma de no personalizarlos o nombrarlos es recurrir a un simple adjetivo calificativo para aludir a ellos, como EL ARTISTA ALTO, EL ARTISTA BAJO, EL ARTISTA GORDO y EL ARTISTA FLACO en Cómo el poder de las noticias nos da noticias del poder (1969), donde también el resto de personajes son designados bajo nombres genéricos: EL PERIODISTA, LA REINA, EL MINISTRO y FOTÓGRAFOS, PERIODISTAS Y LOCUTORES (ibid.: 812) que, a su vez, también «aparecen designados con números» (ibid.: 840). Y, en última instancia, les llega a dar unos nombres absurdos: EL GENERAL FRACASSATI, EL ALMIRANTE COMODISSIMO, EL MARISCAL PERDUTI, EL CAPITÁN BERMUDO y EL ORDENANZA ÓRDENES de Nuestro norte es el Sur, de 1978 (ibid.: 1120).

\section{LA TRAMA}

Entre los ensayos de Morales encontramos algunas reflexiones sobre la tragedia clásica que se enlazan o ligan, como él mismo diría, con su propia 
obra dramática. En concreto, hay cuatro ideas que resultan muy ilustrativas a la hora de adentrarnos en sus piezas teatrales. En primer lugar, la constatación, que aparece en «La Barraca, el Búho y el teatro experimental», de que el drama o la tragedia no son acción, «sino actos y acciones que ocasionan determinadas consecuencias de las que debemos responsabilizarnos» (Morales 2012: 192) ${ }^{7}$. En segundo lugar, la importancia de la tragedia como ars moriendi y que, al imaginarse «la vida en su télos o límite, nos permite entenderla plenamente por ello, ya que la representa en su culminación definitiva» (ibid.: 342). Será en este mismo interesante ensayo, «De la tragedia: un mito de enlace y desenlace», donde analice el mito como ese tejido compuesto de trama, la acción llevada a cabo por el personaje y el público sobre los que parte nuestro estudio y donde encontramos la tercera característica relevante en el teatro de Morales, ese encadenamiento del hombre, su imposibilidad de desatarse. Y junto a ese desconcierto e incertidumbre en que vive el ser humano, no solo en su teatro sino en la realidad contemporánea, aparece una cuarta característica cuyo origen toma de nuevo de la tragedia clásica y que estriba en la forma en que el personaje revela sus ideas y pensamientos a través de sus palabras, 'pronunciándose'.

Por ello, dicho pensamiento hablado participa en contro-versias, que revelan 'estróficamente' o en reversión contradictoria los diferentes aspectos del problema puesto en juego. Esto explica que el lógos de la tragedia aparezca dividido en diá-logos, que evidencian las muchas posibilidades de proponer el conflicto, aun cuando, de tal manera, con palabras e ideas, se acreciente la aporía ['camino sin regreso'] al intentar resolverla (Morales 2012: 357-358).

Si analizamos cada una de esas cuatro características nos damos cuenta de que, en efecto, todas ellas se dan de manera completa y ejemplar en el teatro de José Ricardo Morales. Solo con leer la mayoría de sus piezas comprobaremos que en ellas resulta muy relevante no tanto la acción como las consecuencias que se derivan de las acciones de los personajes y que realmente nos presentan una manera de entender la incertidumbre en la que se sitúa nuestra vida. Como comentaba recientemente y ha reiterado en otras ocasiones nuestro dramaturgo, su teatro «por ser de la incertidumbre, no pertenece al mundo del absurdo, sino que plantea el absurdo del mundo» (Yousfi 2014: 112). Sin embargo, puede aducirse que esas la primera y la tercera características antes citadas no son más que elementos connaturales a toda obra dramática, por lo que vamos a detenernos en esos dos elementos relacionados con la trama, tal y como hemos visto que la entiende Morales, centrada en el lógos o la palabra. Así, estos dos aspectos, que también 'originariamente' proceden de la manera clásica de concebir el teatro, se vinculan, desde el punto de vista del contenido

\footnotetext{
7 También reitera esta misma idea en otro pasaje (Morales 2012: 346).
} 
o argumento fundamental, con la situación de encadenamiento que el hombre padece; $\mathrm{y}$, desde un punto de vista más formal o referido a la manera de hacer avanzar la trama, el estilo parecido a la esticometía o "conversación verso a verso» (Fuentes 2007: 37) que podemos encontrar en los diálogos de buena parte de sus obras.

Ya en una de sus primeras piezas, El embustero en su enredo (1941-1945), Morales utiliza a los Vecinos en la escena final del Cuarto Acto como contrapunto al estado en que se encuentra el protagonista (Morales 2009: 126) para, por un lado, cerrar la obra con un final presumiblemente feliz ante el desconcierto del protagonista: "Celebrad mi desconcierto. Celebradlo. Haya gozo y alegría cuando me encuentro perdido en este mundo de todos» (ibid.: 127); y, por otro, para remarcar la soledad en que vive el personaje. Ese contraste entre el estado real del personaje y la realidad externa que no le corresponde - la incertidumbre y la contradicción permanente en que se encuentra el ser humano- lo podemos ver en otras obras donde, además, el Coro asume el papel de provocar al personaje dramático para indagar en sus pensamientos. Así, en el último acto de Bárbara Fidele, se reproduce un diálogo que se adapta muy bien al estilo y fondo de las tragedias griegas:

BÁRBARA FIDELE: ¿Por qué repites mis pensamientos?

EL DESCONOCIDO: Si eran los suyos, no habérmelos preguntado.

BÁRBARA FIDELE: ¿Estáis todos contra mí? ¿Cómo debo interpretar vuestro ambiguo lenguaje?

EL SOLDADO: Palabras de doble sentido, malas para referirse a una conducta servidora, a una firme defensora de la fe.

BÁRBARA FIDELE: ¿No llevo en todos mis actos el deseo de ser justa? ¿Por qué se apartan de mis propósitos y se vuelven contra mí, trayendo consecuencias imprevistas? ¿Qué naturaleza tienen independiente a mi voluntad? ¡A Dios le pediría que me aniquilase, si este ruego, que expreso para mi mal, no variara también, convirtiéndose en dichoso beneficio! (Morales 2009: 264).

Resulta así que con esa situación sin salida en la que se encuentra el ser humano, y que tan bien refleja Morales en sus obras teatrales, se vuelve a dar importancia al destino trágico, a las consecuencias inevitables y que escapan a la voluntad del hombre. Ya actúe o se deje llevar por las circunstancias en que le ha tocado vivir, nuestro dramaturgo nos presenta a sus personajes como 'prometeos encadenados', incapaces de salir de las coordenadas y consecuencias derivadas no solo de sus acciones, sino de la realidad que los envuelve, de la tecnocracia reinante o de la deshumanización de la sociedad contemporánea. Realidad deshumanizadora y situación de incertidumbre que vuelve a dejar al

\footnotetext{
${ }^{8}$ Para la estructura y recursos más habituales en la tragedia griega, puede consultarse Fuentes González (2007).
} 
hombre solo, trágicamente incapaz de gestionar su vida, sus pensamientos e incluso su muerte.

Respecto a la otra característica 'original' del teatro de Morales, la concepción casi estrófica o versificada de muchos de sus diálogos, podemos ofrecer varios ejemplos donde interesa comprobar cómo esa imitación se traduce no solo en la forma sino, lo que es más importante, en el fondo, es decir en los pensamientos, aforismos, controversia, paradojas, contrastes, ilación de pensamientos y debate que bajo ese intercambio de palabras subyacen. Y resulta interesante para comprobar esas similitudes contrastar dos textos, uno de una tragedia griega y otro de nuestro dramaturgo desterrado, teniendo presente que los elegidos son representativos, en última instancia, de ambos tipos de dramaturgias.

Así, el diálogo entre LA MUJER y EL JEFE en Los culpables, de 1964 nos recuerda al de Antígona frente a Creonte cuando después de que la hayan encontrado enterrando el cadáver de Polinices la hacen prisionera:

EL JEFE: ¿De cuándo acá los inocentes tratan de huir como culpables?

LA MUJER: Frente a los métodos en uso no queda sino huir o combatirlos. Y en cuanto a la inocencia, no soy tan inocente de creer que me detengan con arbitrariedad pero sin intención...

EL JEFE: Así que distribuye literatura clandestina, oculta un arma, intenta evadirse y, por si fuera poco, atribuye intencionalidad a la policía.

LA MUJER: No he dicho nada que no sea verdad.

EL JEFE: ¿A quién estaba dirigido el documento en clave?

LA MUJER: Por lo visto, a usted mismo.

EL JEFE: ¡Basta ya de absurdos!

LA MUJER: En circunstancias tan insólitas, quizá lo razonable sea el absurdo. Si quiere, para mostrarse razonable o absurdo, me deja en libertad (Morales 2009: $333)$.

CREONTE: ¿Y no te da vergüenza distinguirte así de ellos?

ANTÍGONA: No, que honrar a un hermano no es cosa vergonzosa.

CREONTE: Pero, ¿no era tu hermano quien con él se enfrentó?

ANTÍGONA: Hermano y aun nacido del mismo padre y madre.

CREONTE: Entonces, ¿por qué honores rindes al otro impíos?

ANTÍGONA: No dirá el muerto Eteocles que es ésa su opinión.

CREONTE: Si al nivel de un impío te dedicas a honrarle...

ANTÍGONA: Es que no ha muerto un siervo suyo, sino su hermano.

CREONTE: De la tierra enemigo por la que él peleaba.

ANTÍGONA: Tales son, sin embargo, los ritos gratos a Hades.

CREONTE: Mas no es justo que el malo reciba lo que el bueno.

ANTÍGONA: ¿Quién sabe si piadoso resulta eso allá abajo? (Sófocles 1985: 420421, vv. 510-521).

También más adelante, cuando responde María Garcés: «Quise negarles lo que soy para poder negarme a los que son» (Morales 2009: 339), nos viene a 
la memoria esas antítesis y contraposiciones de conceptos que también aparecen en boca de la protagonista sofoclea: «¡Desgraciada de mí que ya ni entre los vivos cuento ni estoy entre los difuntos!» (Sófocles 1985: 433, vv. 850-852).

Observamos idéntico estilo de oraciones cortas, llenas de significados y conceptos, en algunos diálogos de La adaptación al medio, pero José Ricardo Morales ha adoptado dicho estilo al tono irónico y humorístico que tanto caracteriza su escritura:

SANDRO: ¿Así que usted ve fuego?

MATÍAS: Me parece que fumo.

SANDRO: Se engaña.

MATÍAS: ¿Y este humo? (Lanza una bocanada.)

SANDRO: ¿De qué humo me habla?

MATÍAS: De tan preciosa nube. (Lanza otra bocanada.)

SANDRO: No la veo.

MATÍAS: Todo consiste en no querer enterarse.

SANDRO: Consiste en que no puedo verla.

MATÍAS: Le recomiendo un oculista (Morales 2009: 454).

Respuestas, oraciones formadas por una sola línea, palabras enigmáticas y llenas de significados diferentes, contraposiciones o antítesis que evocan también diálogos en trímetros yámbicos, como el que sostienen el adivino Tiresias y el hijo de Layo en Edipo, rey de Sófocles:

TIRESIAS: Yo te parezco loco por lo visto, mas cuerdo soy para el padre y la madre que te dieron el ser. (Vuelve a hacer que se va.)

EDIPO: (Reteniéndole.) ¿Para quiénes? Espera. ¿Qué padres me engendraron?

TIRESIAS: En este mismo día tendrás linaje y muerte.

EDIPO: ¡Qué enigmático todo, qué oscuro lo que dices!

TIRESIAS: ¿No eres tú quien mejor descifraba esas cosas?

EDIPO: ¡Sí, búrlate de aquello donde está mi grandeza!

TIRESIAS: Pues bien, son esos éxitos lo que ahora te pierden (Sófocles 1985: 248-249, vv. 435-442).

En algunas páginas posteriores de esa misma obra o en casi todo el diálogo entre los dos personajes -EL HOMBRE y LA MUJER - de Oficio de tinieblas, de El segundo piso, de El material (1972), de No hay que perder la cabeza y de Aquí hay gato encerrado, de 2007 (Morales 2009: 521-532, 541-556, 1006 y 709-727, respectivamente), se vuelve a ese estilo de réplica-oración que aúna el estilo de los aforismos con la característica estructura de los estásimos ${ }^{9}$ (estrofa y antiestrofa) de las tragedias griegas. También se entrecortan e inte-

\footnotetext{
${ }^{9}$ Según Aristóteles, las partes de la tragedia, «desde el punto de vista cuantitativo y en las que se divide por separado, son las siguientes: prólogo, episodio, éxodo y parte coral, y ésta se subdivide en párodo y estásimo» (Aristóteles 1974: 7)
} 
rrumpen las recitaciones de Cerino y Cerino B en Miel de abejas, como si se tratara de las diferentes partes cantadas por el Coro trágico (ibid.: 592-593), y volvemos a encontrar este estilo de réplica-oración en La adaptación al medio (ibid.: 459).

Esa voz múltiple, dividida en diversas intervenciones como si de un eco o coro de voces se tratase, la encontramos también en la farsa Cómo el poder de las noticias nos da noticias del poder o en el ensayo dramático El inventario (ibid.: 840-845 y 863-864), donde se parodia, además, ese lenguaje de formulario y respuesta concisa propio de la burocracia moderna, de la programación informática o de los experimentos científicos (ibid.: 874-875, 877 y 885). A la vez que se desarrolla un tipo de diálogo absurdo repleto de juegos de palabras como en La imagen (ibid.: 1029, 1042 y 1044), en Este jefe no le tiene miedo al gato (ibid.: 1076-1077, 1081 y 1083) y en El torero por las astas, de 1983:

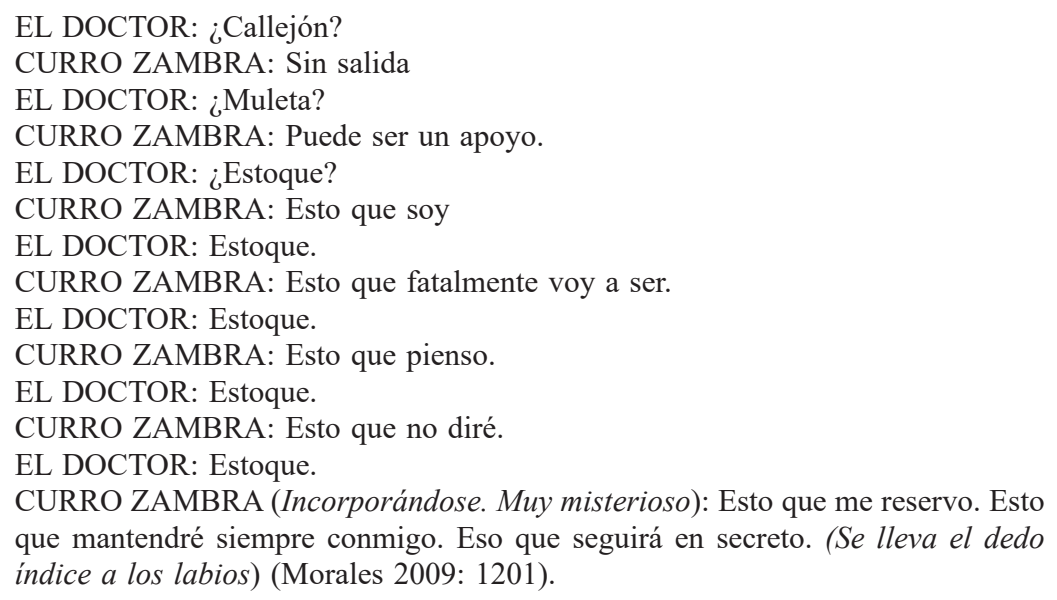

\section{El PÚBLICO}

Cuando Morales analiza la catarsis en «De la tragedia: un mito de enlace y desenlace», establece la importancia del público como elemento imprescindible y vital de la tragedia, al vincularlo el espectáculo con la reacción de los espectadores ante lo representado. Por otro lado, ese mismo ensayo nos llama la atención sobre dos aspectos de la Poética de Aristóteles ${ }^{10}$ :

${ }^{10}$ Como afirma Aristóteles (1974: 8) en su Poética: «el temor y la compasión pueden nacer del espectáculo, pero también de la estructura misma de los hechos, lo cual es mejor y de mejor poeta». 
Los dos extremos que afectan al espectador sujeto a las tensiones de la trama. Son éstos. Por un lado, como queda dicho, éleos ('compasión', la ayuda mental del espectador al personaje atado y abatido por el sufrimiento) y phóbos ('temor', quizá la intención de huir ante lo pavoroso), efectos que mueven miméticamente al espectador, produciéndole el deseo de socorrer a la víctima trágica o de correr despavorido ante lo que le sucede a ésta (Morales 2012: 365).

Ya hemos tenido ocasión de comprobar cómo nos encontramos con verdaderos personajes trágicos en algunas de sus obras. Por ejemplo, en Bárbara Fidele, donde la protagonista, como Edipo, será la única responsable de su propia desgracia, aunque fuera de manera involuntaria; o Gonzalito y María Garcés en Los culpables para demostrar que nadie puede escapar a un poder convertido en verdugo de sus propios ciudadanos; o ese Orfeo que no puede huir tampoco, en su actualización contemporánea $-\mathrm{y}$ versión publicitaria-, de su fatal muerte en Orfeo y el desodorante. Sin embargo, y quizás sea aquí donde Morales no siga a sus 'originales' clásicos, el distanciamiento irónico, la situación absurda de esta sociedad contemporánea, dominada por la vana propaganda política o publicidad consumista, no nos permite otra cosa que intentar 'correr' despavoridos, aunque sin éxito, para huir de la incertidumbre que nos rodea. No olvidemos que hasta las tres parcas en El destinatario se rinden ante los males de la globalización o que incluso en Orfeo y el desodorante se nos demuestra la inutilidad de esos descensos míticos al infierno, pues es infernal ya la situación que nos rodea.

Como bien señala Claudia Ortego Sanmartín (1995: 13), las circunstancias del exilio le han dado a Morales esa «óptica desprendida y lejana, una peculiar manera de percibir el mundo que ha dado una configuración propia a su dramaturgia». Así que en muchas obras no hay víctima inocente o sacrificada sin culpa alguna, sino una verdadera denuncia de la locura e incertidumbre. La deshumanización de los personajes nos lleva a distanciarnos de sus aventuras o desventuras emocionalmente, pero nos permite, por otro lado, entender de manera más racional los múltiples aspectos, situaciones y asuntos inexplicables de la época en que vivimos. Por tanto, más que a 'socorrer' o 'correr' - compadecerse o sentir miedo-, Morales nos invita a 'descorrer', como él, las cortinas que dominan el espacio escénico, para dejar que la luz de su ironía y su humor iluminen las sombras de corrupción, abuso de poder y tecnocracia actuales. Es decir, nuestro dramaturgo presenta la realidad ante nuestros ojos de manera distanciada e irónica para conseguir 'descorrer' los opacos cortinajes que impiden darnos cuentas de los grandes sinsentidos de la sociedad actual; en una palabra, 'desvelar' sobre la escena la complejidad del mundo contemporáneo

Estamos, por tanto, ante un teatro que da la vuelta y se burla a veces de temas y tópicos clásicos, como en La odisea, Hay una nube en su futuro, Orfeo y el desodorante, Edipo reina o la planificación; y que nos llama la atención 
incluso sobre la amenaza permanente de 'embargo' que pende sobre el propio teatro, como se describe al principio de la Jornada Segunda de Colón a toda costa o el arte de marear:

DON CRISTÓBAL: Que le aproveche. Porque nos embargó el cisne de Lohengrin, el arca de Noé, la gran serpiente de Quetzacoatl...

FILOMELA: El caballo de Troya, la escala cromática, el diván de Tamarit...

DON CRISTÓBAL: Los cuatro jinetes del Apocalipsis, los trabajos de Hércules, la caja de Pandora...

FILOMELA: El arpa de David y el violín de Ingres. ¿Te afectó mucho?

DON CRISTÓBAL: En absoluto. Ahora veo más claro. Al despojarnos de tantos trastos viejos, pertenecientes a obras olvidadas o a los proyectos nunca concluidos, me despejó a la vez el campo y la cabeza. Sin embargo... (Morales 2009: 1309).

En efecto, ni el mismo teatro se escapa a situaciones que pueden, esta vez sí, producirnos ganas de 'correr' y 'socorrer' al mismo autor de la obra representada. Denuncia así Morales algunas de las actualizaciones de los grandes clásicos que, de tanto querer ser originales, nos hacen olvidarnos de la originaria raíz de donde procede. Mal que, como nos recuerda también Morales en boca de dos de las parcas de El destinatario, Láquesis y Átropos, acabarán padeciendo casi todos los escritores:

LÁQUESIS: ¿No has visto Los hermanos Karamazov representados en un teatro circo, mediante un equilibrista mudo y un virtuoso del trapecio que hablaba boca abajo? ¿No escuchaste un preludio de Bach usado como música de fondo en la presentación de un nuevo detergente? Inclusive, los versos que acabas de citar, ¿no estuvieron primero dedicados a la juventud?

ÁTROPOS: ¿Y qué importa el poema original, si el destino de todos los autores se encuentra sometido a las intervenciones muy dudosas de la posteridad? (...) (Morales 2009: 1376).

Por otro lado, los guiños al público actual son constantes pues, incluso en aquellas obras más ambientadas o fieles al modelo clásico, puesto que «los personajes mantienen sus nombres y visten a la usanza de la antigua Grecia» (Morales 2009: 1355), nos encontramos con que aparecen el micrófono, la televisión y la publicidad, así como la Esfinge reducida a un mero invento con música y luces (ibid.: 1359 y 1363-1364).

Sin embargo, su situación de desterrado, de autor a caballo entre dos mundos —España y Chile - pero de ninguno de los dos en concreto ${ }^{11}$, así como su 'problematización' de la situación presente le convierten, como él mismo matiza, en un dramaturgo «condenado a la postumidad» o, en todo caso, a escribir

${ }_{11}$ «[E]l desterrado es el que tiene dos tierras para no tener ninguna. El poseer conciencia de ello, le permite ser el que es: un enajenado cuerdo que puede sacar partido de su propia situación, pues vive en la inmediatez de lo ajeno» (Godoy y Ahumada 2013: 148). 
«un teatro que sea vigente o que anticipe algo que pueda ser vigente» (Yousfi 2014: 112 y 113). También el investigador Pablo Valdivia (2015: 62-63) ha estudiado cómo ese carácter de 'renovación' se cumple en todas las acepciones del diccionario que podamos encontrar y lo enlaza con la idea de 'extrañamiento’ que impera en la propia vida y obra teatral de José Ricardo Morales.

Huelga, entonces, la pregunta sobre para qué público escribía Morales pues todos ellos confluyen en ese 'posible' teatro que aspira a ser representado algún día o época lejana. Sin embargo, no ha sido necesario esperar, como sabemos que ocurre con otros dramaturgos exiliados, ni se ha cumplido su condena a la 'postumidad', pues en la primavera de 2014 el Centro Dramático Nacional llevó a cabo en Madrid un ciclo donde se representaron algunas de sus piezas teatrales: La corrupción al alcance de todos, Las horas contadas, Sobre algunas especies en vías de extinción y Oficio de tinieblas ${ }^{12}$. Y tanto los directores como espectadores y críticos han podido darse cuenta de la profunda originalidad de sus planteamientos en temas absolutamente vigentes pero que inciden en conflictos universales (Valdivia 2015) ${ }^{13}$. Esa sin duda es la grandeza de la dramaturgia de este escritor des-terrado.

\section{CONCLUSIÓN}

La pervivencia y revisión de mitos clásicos resultan una constante en el teatro de muchos dramaturgos españoles exiliados tras la guerra civil: M. ${ }^{a}$ Luisa Algarra, José Bergamín, José María Camps, José Martín Elizondo, María Zambrano, etc.; no obstante, destaca la asiduidad con que aparecen en la obra de este escritor desterrado en Chile. Todos los posibles ciclos míticos de la tragedia aparecen sobre escena: troyano, tebano, grandes héroes. Sin embargo, esta alusión y recorrido por los principales hitos o representaciones de la Grecia clásica le ayudan a incidir y reflejar uno de los temas más relevantes de su teatro: la crítica a la sociedad moderna, consumista y llena de sinsentidos. Además, ese interés no se limita a una época determinada dentro de su producción dramática, sino que aparecen elementos y recursos desde sus primeras obras, como Pequeñas causas (1946) y Bárbara Fidele (1944-1946) hasta sus obras más recientes, como Edipo reina o la planificación (1999) y El destinatario (2002). Tampoco viene condicionado por la extensión de dichas piezas, ya que pueden ser breves o bien incluirse dentro de sus llamadas 'Obras mayores'. Del mismo modo, se alternan y se suceden los posibles subgéneros, desde un carácter más trágico al tono característico de la farsa.

12 Vid.: http://cdn.mcu.es/wp-content/uploads/2014/03/DOSIER-JOSE-RICARDO2.pdf

13 Además del artículo de Pablo Valdivia en Primer Acto, puede consultarse el Dossier que la revista Laberintos dedica al dramaturgo en 2014. 
Con la interpretación realizada sobre el teatro de José Ricardo Morales de aquellos tres elementos que, en su opinión, deben estudiarse en la tragedia de García-Lorca y, de manera extensiva, a toda tragedia — personajes, trama y público-, esperamos haber demostrado cómo el dramaturgo exiliado se distancia del objetivo de escribir una tragedia de ligazón sobre una familia en concreta, castigada por el destino o por unos dioses inmisericordes, como podemos encontrar en las tragedias basadas en los ciclos troyanos y tebanos. Tampoco sus personajes resultan próximos, identificables para el público o lector, sino que Morales aplica un distanciamiento irónico, a través del anonimato y de la deshumanización, que le lleva, en muchos casos, a dar un papel destacado al coro como parte integrante de sus obras, debido a la disolución que comporta de un personaje concreto y bien caracterizado en un ente colectivo y representante de un grupo, no de un individuo.

Por otro lado, Morales utiliza muchos elementos de la tragedia clásica griega para lograr la desmitificación del argumento y la trama presentados, como pueden ser los juegos de palabras, la ironía, el distanciamiento, el metateatro, la actualización y el anacronismo paródico. Quizás, de esta forma, transmite a esos mitos heredados ese extrañamiento que observa en el mundo que le rodea y que quiere comunicar a cuantos le lean o escuchen. Es su manera de recordar y compartir su situación de desterrado y, a la vez, de alertarnos sobre esa realidad absurda que impera gracias a la propaganda, la publicidad, la tecnología o el desarrollo. Así nos lo advierte en una de sus primeras piezas dramáticas, a través de la cita de Pericles que recogió el historiador Tucídides y que Morales incluye al principio de Edipo reina: «El curso de los acontecimientos puede ser tan estúpido como los planes que los hombres hacemos. Por tal razón atribuimos al azar cuanto sucede contra lo que esperamos» (Morales 2009: 1337). Buena forma de luchar contra el destino trágico que caracteriza a las tragedias de las que se nutre.

De todo lo anterior se deduce que tampoco el tercer elemento que entraría en juego como parte activa del espectáculo teatral —el público- funciona según el sentido de la 'catarsis' que el propio Morales ha glosado: ese movimiento de 'correr' o 'socorrer' que va asociado a las tragedias. El distanciamiento que consigue con la caracterización de los personajes, con los recursos metateatrales y con esos diálogos que suenan a conversación ya tenida y sabida - y, por tanto, olvidada - provoca que los espectadores no puedan identificarse e implicarse con cuanto acontece a sus ojos. Sin embargo, resulta interesante comprobar cómo José Ricardo Morales logra en todas sus piezas invitar a la reflexión, a alejarse de las posturas u opiniones comúnmente aceptadas. Ese 'descorrer' con que, siguiendo su gusto hacia las etimologías y juegos de palabras, hemos definido la reacción que espera lograr de su público, aparece, por tanto, como sinónimo de volver al inicio del camino 'recorrido', pero también como obligación casi ineludible a 'no correr', a tomarse tiempo 
para pensar con calma y no dejarse llevar por la 'corriente' de pensamiento único y negador de la evidencia que nos rodea.

\section{BIBLIOGRAFÍA CITADA}

AA.VV. (2014). «Dossier: José Ricardo Morales», Laberintos. 16, pp. 186-315. Accesible en http://bv.gva.es/documentos/lab16.pdf [última consulta en marzo de 2016].

Ahumada, Haydée (2002). «Viajero esencial: José Ricardo Morales y su teatro del exilio», Acotaciones: revista de investigación teatral. 9, pp. 45-63. Accesible en http://www. resad.es/acotaciones/acotaciones9/9ahumada.pdf [última consulta en enero de 2017].

Alberti, Rafael (2006). De un momento a otro. El adefesio, Gregorio Torres Nebrera (ed.). Madrid: Cátedra.

Aristóteles (1974). Poética, trad. Valentín García Yebra. Madrid: Gredos. Accesible en http:// www.ugr.es/ zink/pensa/Aristoteles.Poetica.pdf [última consulta en marzo de 2016].

Aznar Soler, Manuel (2009). «El teatro en su exilio chileno de José Ricardo Morales (19381992)», en José Ricardo Morales, Obras completas, 1. Teatro, edición, estudio introductorio y bibliografía de Manuel Aznar Soler. Valencia: Institució Alfons el Magnànim, pp. 23-24.

Bergamín, José (1945). La hija de Dios. La niña guerrillera. México: Manuel Altolaguirre Impresor.

Centro Dramático Nacional-Prensa (2014). Ciclo José Ricardo Morales. Laboratorio Rivas Cherif. Presentación de las tres obras que se representaron en abril-mayo en el Teatro María Guerrero. Accesible en http://cdn.mcu.es/wp-content/uploads/2014/03/DOSIER-JOSE-RICARDO2.pdf

Doménech, Ricardo (2013). El teatro del exilio. Madrid: Cátedra. Edición de Fernando Doménech Rico.

Eurípides (1998). Tragedias, I, ed. Juan Antonio López Férez. Madrid: Cátedra.

Fuentes González, P. P. (2007). «Los elementos estructurales del drama griego antiguo: forma y función», Florentia Liberritana. Revista de Estudios de Antigüedad Clásica. 18, pp. 27-67.

Godoy Gallardo, Eduardo y Haydée Ahumada Peña (2013). «José Ricardo Morales y su contexto Literario creativo», Mapocho. Revista de humanidades. 74, pp. 147-158.

Gómez, Juan y Deluca, Pablo (1992). «Entrevista con José Ricardo Morales», Anthropos. 133 (junio), p. 87.

Gracia, Teresa (1984). Las republicanas. Valencia: Pre-Textos.

Morales, José Ricardo (1973). «Peregrino en su patria y autor de ninguna parte», Triunfo. 563 (julio), pp. 34-36.

Morales, José Ricardo (1992). «Autobiograma», en Manuel Aznar Soler (ed.), José Ricardo Morales. Un dramaturgo del destierro. Creación dramática y pensamiento crítico, Anthropos. 133 (junio), número monográfico, pp. 21-27.

Morales, José Ricardo (2009). Obras completas, I. Teatro, edición, estudio introductorio y bibliografía de Manuel Aznar Soler. Valencia: Institució Alfons el Magnànim.

Morales, José Ricardo (2012). Obras completas, II. Ensayos, edición, estudio introductorio y bibliografía de Manuel Aznar Soler. Valencia: Institució Alfons el Magnànim.

Ortego Sanmartín, Claudia (1992). «Reflexiones sobre Españoladas», Anthropos. 133 (junio), pp. 80-86. 
Ortego Sanmartín, Claudia (1995). «Introducción» en José Ricardo Morales, Cuatro imposibles. Sant Cugat del Vallès: Associació d'Idees-GEXEL (Winnipeg, 1), pp. 9-40.

Ortego Sanmartín, Claudia (1999). «Dónde estás, Libertada, dónde estás», en Manuel Aznar Soler (ed.), El exilio teatral republicano de 1939. Sant Cugat del Vallés: Associació d'Idees-GEXEL, pp. 303-330.

Ortego Sanmartín, Claudia (2002). «José Ricardo Morales: un escritor en el 'aparte' del destierro», en José Ricardo Morales, Teatro ausente. Sada: Ediciós do Castro, Biblioteca del Exilio, pp. 7-67.

Ortego Sanmartín, Claudia (2003). «Morales y los escenarios: historia de una ausencia», Primer Acto. 298 (abril-mayo-junio), pp. 36-38.

Santa María Fernández, María Teresa (2016). «Mitos y tradición grecolatina», en Verónica Azcue y M. ${ }^{\mathrm{a}}$ Teresa Santa María Fernández, Mito y tradición en el teatro del exilio republicano de 1939. Sevilla, Renacimiento (Biblioteca del exilio. Anejos, XXXIX), pp. 137-258.

Sófocles (1985). Tragedias, introducción y versión rítmica de Manuel Fernández-Galiano. Barcelona: Planeta.

Valdivia, Pablo (2011). Aproximación al teatro de José Ricardo Morales. Trabajo fin de Máster, dirigido por José Romera Castillo. Accesible en http://www2.uned.es/centro-investigacion-SELITEN@T/pdf/tfm/Pedro_Valdivia.pdf [última consulta en marzo de 2016].

Valdivia, Pablo (2014). José Ricardo Morales de mar a mar. Sevilla: Renacimiento.

Valdivia, Pablo (2015). «Renovación en la obra de José Ricardo Morales», Primer Acto. Cuadernos de investigación teatral. II, 349, pp. 61-69.

Yousfi, Yasmina (2014). «Conversaciones con José Ricardo Morales», Puentes de Crítica Literaria y Cultural. 2, pp. 110-116.

Fecha de recepción: 3 de marzo de 2016.

Fecha de aceptación: 25 de noviembre de 2016. 